\title{
Antibacterial Screening of Gunnera perpensa-Mediated Silver Nanoparticles
}

\author{
Naazlene Patel, Kabange Kasumbwe, and Viresh Mohanlall \\ Department of Biotechnology and Food Technology, Faculty of Applied Sciences, Durban University of Technology, \\ P. O. Box 1334, Steve Biko Campus, Durban 4001, South Africa
}

Correspondence should be addressed to Viresh Mohanlall; vireshm@dut.ac.za

Received 17 March 2020; Accepted 23 April 2020; Published 21 May 2020

Academic Editor: Eduard Llobet

Copyright $\odot 2020$ Naazlene Patel et al. This is an open access article distributed under the Creative Commons Attribution License, which permits unrestricted use, distribution, and reproduction in any medium, provided the original work is properly cited.

The biosynthesis of nanoparticles has become quite popular and has been proposed as an alternative over the tedious, expensive, and toxic physical and chemical methods of synthesis due to its cost-effectiveness and ecofriendliness. This study involved the biosynthesis, characterization, and evaluation of the antibacterial activity of Gunnera perpensa-mediated AgNPs. Biosynthesized AgNPs were characterized using TEM, UV, and FTIR spectroscopy. The antimicrobial activity was evaluated in six bacterial strains, using the disc diffusion assay, and MIC was determined using the broth dilution assay. All NPs generally presented as spherical clusters, with sizes ranging from 13 to $24 \mathrm{~nm}$, as determined by TEM. The absorption peaks ranging between 421 and $425 \mathrm{~nm}$ and the presence of the $\mathrm{C}=\mathrm{O}$ bond with amine groups, as indicated by UV and FTIR spectra, confirmed the synthesis and stabilization of G. perpensa extract-mediated AgNPs. Good antimicrobial activity ranging from 7.0 to $9.0 \mathrm{~mm}$ was exhibited by both preparations of $G$. perpensa extract-mediated AgNPs against both Gram-positive and Gram-negative studied bacteria, at MIC ranging from 3.2 to $12.5 \mu \mathrm{g} / \mathrm{ml}$. Overall, good antibacterial activity was achieved at lower doses with both preparations of the G. perpensa-mediated AgNPs against all tested bacterial strains, suggesting G. perpensa-mediated AgNPs as good antimicrobial agents.

\section{Introduction}

Over the years, nanotechnology has emerged as a fastgrowing field with its application in nanomedicine, drug delivery, therapeutics, and diagnostics. This technique involves the manipulation of matter on an atomic and molecular scale which results in nanodevices or materials known as nanoparticles (NPs) possessing unique electrical, optical, and physicochemical properties [1]. These NPs include gold $(\mathrm{Au})$, silver (Ag), selenium (Se), iron oxide, and platinum (Pt), to name a few; and amongst these, AgNPs are the most frequently researched nanoparticles [2].

For centuries, AgNPs have been known for their antimicrobial action and hence have been commonly used in pharmaceutical and medical devices [3]. These NPs are composed of silver or silver oxide, ranging in size from 1 to $100 \mathrm{~nm}$. They are biodegradable, biocompatible, tunable, and possess a surface that can be modified synthetically These NPs can be synthesized by physical and chemical methods. However, due to toxic chemicals used, expensive equipment needed, and high laborious, environmentally safe, low-cost, rapid, and easily scaled up synthesis methods are needed. Biosynthesis has thus solved this problem by eliminating the need for high pressure, energy, or toxic chemicals and is an area of research that is becoming quite popular [4]. In recent years, various researchers have demonstrated the biosynthesis of AgNPs using bacteria, actinomycetes, fungi, and plants, in which the NPs are produced extracellularly and are stable in solution $[4,5]$. Plants have been successfully used for AgNP synthesis due to their potential medicinal properties, huge availability, and faster rate of synthesis [6]. Many plants have been previously used to study the synthesis of AgNPs, most of which involve the use of leaf extracts [7-9]. According to Burlacu et al. [10], proteins, polyphenolics, and water-soluble heterocyclic 
components found in plants are mainly responsible for the reduction of silver salts and the stabilization of the NPs.

G. perpensa belongs to the family of Gunneraceae. It is commonly referred to as river pumpkin [11]. The Zulu name "ughobo" refers to the flowing of fluids and its use in traditional medicines to remove excess fluid from the body [12]. The roots are up to $300 \mathrm{~mm}$ thick, and the leaves arise from a central tuft near the top of the apex. These leaves are large, kidney-shaped, dark bluish green, and covered with hairs on both surfaces. The flowers are small, tiny, and reddish brown and protrude from a long spike which is taller than the leaves. It is an obligate wetland plant that is found in marshy areas and along streams. It is unable to tolerate frost and cold conditions [13]. It is used by the rural population for the treatment of dysmenorrhea, and aqueous extractions have been used to relieve rheumatoid pain, assist in childbirth, and treat female infertility [14]. The rhizomes have been proven to have analgesic and anti-inflammatory properties [15]. In South Africa, a decoction of the roots is used to expel the placenta after birth and relieve menstrual pain [16]. Caffeic acid, quercetin, ellagic acid, and ellagitannins, as well as two anthocyanins, are present, whereas alkaloids, cyanogenic glycosides, iridoids, proanthocyanidins, saponins, and sedoheptulose were not detected in certain Gunnera species [17]. Derivatives of 1, 4-benzoquinones and transphyt-2-enol were found in methanol extracts of leaves of $G$. perpensa [18]. Plant extracts act as both reducing agents and capping agents for the reduction of silver and stabilization of NPs. This phenomenon is attributed to the presence of phytochemicals within the plant extracts such as proteins, flavonoids, alkaloids, sugars, and phenolic acids. High levels of polyphenolic substrates found in $G$. perpensa contribute to the antibacterial activity of the green-synthesized AgNPs.

Therefore, this study focused on synthesizing, characterizing, and assessing the antibacterial activity of AgNPs prepared from the aqueous/methanolic extracts of G. perpensa plant leaves.

\section{Experimental}

2.1. Materials. Mueller Hinton agar plates, microtiter plates, and Mueller Hinton broth (MHB) were purchased from BioRad Laboratories (Richmond, VA, USA). Bacterial cultures were obtained from Lancet Laboratories (SA). Microbank vials were purchased from Davies Diagnostic (SA). All chemicals were of analytical grade and were supplied by Sigma-Aldrich (St Louis, MO, USA).

\subsection{Methods}

2.2.1. Collection of Plant and Preparation of Leaf Extracts. Plant G. perpensa was obtained from around Durban, KwaZulu Natal, South Africa. Its leaves were washed twice with tap water and air-dried at room temperature. Leaf extraction was done as previously described by Dubey et al. [19] with minor modifications. In brief, $50 \mathrm{~g}$ of thoroughly washed leaves were finely cut and boiled in $250 \mathrm{ml}$ autoclaved distilled water for 20 minutes. The extract was cooled down and filtered with Whatman No. 1 filter paper. Thereafter, the filtrate was sterilized with a syringe filter through a $0.22 \mu \mathrm{m}$ pore filter (Millipore) and was stored at $4^{\circ} \mathrm{C}$ for further use. The same procedure was carried out for the methanol extract, but instead of water, methanol was used as a solvent.

2.2.2. Green Synthesis of Silver Nanoparticles. Initially, $1 \mathrm{M}$ silver nitrate $\left(\mathrm{AgNO}_{3}\right)$ was prepared with sterile distilled water in an Erlenmeyer flask. From this, $60 \mathrm{ml}$ of $1 \mathrm{mM}$ $\mathrm{AgNO}_{3}$ solution was prepared to which $2.5 \mathrm{ml}$ of the aqueous/methanolic leaf extracts were added separately at room temperature. Thereafter, the colourless solution was mixed on a stirrer for 5 minutes and visually observed for a yellow-brown colour change indicative of the formation of AgNPs [19]. The solutions that produced a positive colour change were then stored at $4^{\circ} \mathrm{C}$ in glass bottles.

\subsection{Characterization of the Synthesized Nanoparticles}

2.3.1. Ultraviolet (UV) Spectroscopy. The formation and stability of AgNPs were analysed by UV-visible (vis) spectroscopy using a Varian Cary 100 UV-Vis spectrophotometer containing a Win UV software. A scan in the wavelength range of 200 to $800 \mathrm{~nm}$ was carried out. Samples were poured into quartz cuvettes, placed into the spectrophotometer, and a scan in the wavelength range of 200 to $800 \mathrm{~nm}$ was carried out. Thereafter, the absorbance measurements in relative light units (AU) were recorded.

\subsubsection{Transmission Electron Microscopy (TEM). TEM was} used to determine the morphology and particle size of the synthesized AgNPs. Sample preparations involved centrifugation of AgNP solutions at $1300 \mathrm{rpm}$ for 45 minutes, followed by discarding of the supernatant and resuspending of the precipitants in distilled water. From this, a drop of each sample was then placed on a carbon-coated copper grid and allowed to air-dry at room temperature before loading into the transmission electron microscope for analysis. The microscope used was a JEOL JEM-1010 transmission electron microscope with a Megaview III camera and iTEM UIP software (Tokyo, Japan) accessed from the University of Kwa-Zulu Natal (Westville Campus, South Africa).

\subsubsection{Fourier-Transform Infrared (FTIR) Spectroscopy.} FTIR analyses were also used to identify if the same biomolecules were responsible for the synthesis and capping of the AgNPs for the different extracts. At the onset, sample preparations involved centrifugation of AgNP solutions at $1300 \mathrm{rpm}$ for 45 minutes, followed by discarding of the supernatant and resuspending of the precipitants in distilled water. From this, a drop of the sample was then placed on a PerkinElmer, Spectrum 100 FTIR spectrophotometer and a scan measuring transmittance percentage over the range of wavenumbers from 500 to $4000 \mathrm{~cm}^{-1}$ was taken. Thereafter, E-FTIR software was used to analyze the results and ascertain peak values which were then interpreted. 
2.3.4. Bacterial Cultures and Maintenance. The six bacteria used were Gram-negative E. coli (B3578), E. coli (U10948), and E. coli (P4055) and Gram-positive S. aureus (S6158), S. aureus (P4215), and S. aureus (S5878) and are differentiated by their reference codes following the species name designating their site of isolation from the host. S. aureus and $E$. coli were selected as a target for antimicrobial susceptibility because both bacteria are rapidly growing microorganisms. E. coli has a short generation time of about 15-20 minutes compared to $S$. aureus which has a generation time of about 30 minutes.

All bacterial cultures were plated out and verified. Stock cultures were stored in microbank vials using 50\% glycerol. When required, the cultures were grown in $\mathrm{MHB}$ for 24 hours at $37^{\circ} \mathrm{C}$. The absorbance of bacterial cells was adjusted to MacFarland Standard of 0.5 which corresponds to $10^{8} \mathrm{CFU} / \mathrm{ml}[20]$.

2.3.5. Antibacterial Activity of the AgNPs. The antibacterial activity of aqueous and methanolic AgNPs prepared using the plant extract of $G$. perpensa was investigated using the agar disk diffusion assay as previously described [21]. In brief, $100 \mu \mathrm{l}$ of each tested bacterium was swabbed onto Mueller Hinton Agar plates using a sterile cotton swab. Then, $15 \mu \mathrm{l}$ of AgNP sample solutions $(30 \mu \mathrm{g} / \mathrm{ml})$ were pipetted onto $5.5 \mathrm{~mm}$ sterile filter paper (Whatman No. 1) disks and air-dried in a biological safety cabinet. The treated discs were thereafter placed on the surface of the inoculated bacterial plates and incubated at $37^{\circ} \mathrm{C}$ for 24 hours. Control disks with $100 \%$ DMSO served as the negative control, whilst those with $\mathrm{AgNO}_{3}(30 \mu \mathrm{g} / \mathrm{ml})$ served as the positive control. All tests were carried out in triplicate. The susceptibility of the tested bacteria was determined by measuring the diameter of the zone of inhibition.

2.3.6. Determination of Minimum Inhibition Concentration (MIC). The MIC values for AgNP sample solutions with bacteria activity were determined using microtiter plates. In brief, a serial dilution was done from the concentration of $50 \mu \mathrm{g} / \mathrm{ml}$ to $1.125 \mu \mathrm{g} / \mathrm{ml}$. One well contained DMSO which served as a negative; another well contained MHB which served as a sterility control, and another well contained MHB plus the test bacteria serving as the growth control. Then, $100 \mu \mathrm{l}$ of bacterial culture was added to each well except the sterility controls, and the microplates were sealed and incubated overnight at $37^{\circ} \mathrm{C}$ for 12 hours. After incubation, $50 \mu \mathrm{l}$ of $2 \mu \mathrm{g} / \mathrm{ml}$ growth indicator $p$-iodonitrotetrazolium (INT) was added to each well, and the plates were incubated further for 30 minutes. Growth inhibition was indicated by colourless suspensions, whereas growth was seen as violet coloured suspensions [21].

2.3.7. Statistical Analysis. Antibacterial activity studies were performed in triplicate, and the results were expressed as mean \pm standard deviation (SD). Data were analysed by twoway ANOVA and $t$-test using GraphPad Prism 6.0, and statistically significant values were indicated by $p<0.05$.

\section{Results and Discussion}

3.1. Synthesis of AgNPs, UV-Vis Spectroscopy, and TEM Analysis. Metal nanoparticles are well known for their unique properties, particularly, optical, as a result of surface plasmon resonance (SPR). Thus, the successful formation of AgNPs was confirmed with colour change and UV-Vis spectroscopy.

The AgNPs prepared by mixing the plant extract of $G$. perpensa with $\mathrm{AgNO}_{3}$ solution were successfully synthesized. This was indicated by the colour change of the reaction mixture from colourless solution to yellowish-brown solution (Figure 1). The colour change can be attributed to the reduction of silver ions $\left(\mathrm{Ag}^{+}\right)$from silver nitrate into AgNPs by active biomolecules present in the plant extract [22]. The colour of AgNPs is due to the excitation of SPR arising due to the collective oscillation of free conduction electrons induced by an interacting electromagnetic field [2]. Furthermore, the characteristic absorption band of AgNPs is known to range between $400 \mathrm{~nm}$ and $425 \mathrm{~nm}$ The absorption bands observed for tested sample preparations ranged between $421 \mathrm{~nm}$ and $425 \mathrm{~nm}$ (Figure 2), thus confirming the successful preparation of AgNPs by this extract. TEM analysis was able to give a clear image of AgNPs and determined the size, shape, and distribution of the particles. All synthesized NPs appeared spherical in shape with uniform distribution, ranging from $13 \mathrm{~nm}$ to $24 \mathrm{~nm}$ (Figure 3).

3.2. FTIR Analysis. FTIR measurements were carried out to identify the major functional groups/biomolecules on the surface of the plant extract and its possible involvement in the capping and stabilization of the AgNPs. It was also used to identify if there was any link between AgNPs formed from aqueous and methanolic extracts. Figures 4(a) and 4(b) show the spectra of AgNPs formed with aqueous and methanolic G. perpensa extracts. The intense peaks at 3289, 2973, 1634, and $1635 \mathrm{~cm}^{-1}$ observed were assigned to stretching vibration of $\mathrm{N}-\mathrm{H}$ of amines, $\mathrm{O}-\mathrm{H}$ of alcohol, and $\mathrm{C}=\mathrm{O}$ of carboxylic acid or ester [23]. The presence of amide and carboxylic acid bonds in both samples confirmed the presence of protein polymers in the leaf extract which could be involved in the reduction of $\mathrm{Ag}^{+}$to $\mathrm{Ag}^{0}$ [22]. Biomolecules are known to interact with metal salts via these functional groups and aid their reduction to NPs [24]. Figures 4(a) and 4(b) further show that the methanolic sample of AgNPs synthesized from $G$. perpensa formed higher intensity peaks compared to the aqueous AgNPs. This suggested that methanolic samples were able to elute more polar compounds and hence provided greater stability when compared to their aqueous NP counterparts.

3.3. Antibacterial Activity. AgNPs are well known for their antimicrobial activity, which is said to be attributed to the electrostatic interaction that occurs between the negatively charged cell membrane of the microorganism and the positively charged AgNPs [25]. The accumulation of AgNPs on the cell membrane is believed to alter the membrane causing it to lose permeability which leads to cell death [26]. 


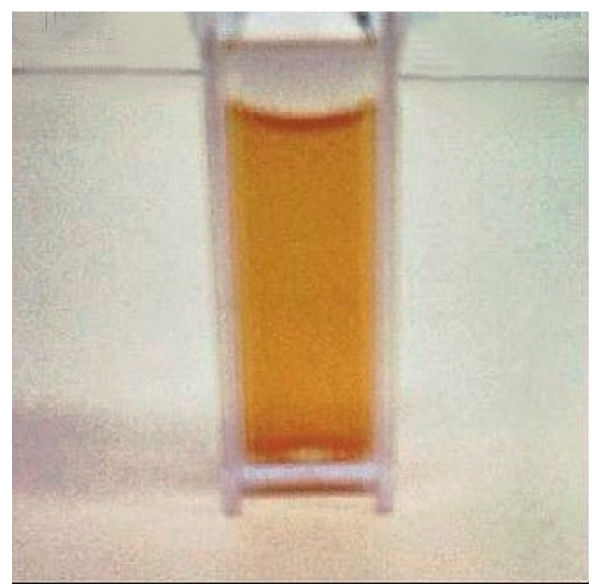

(a)

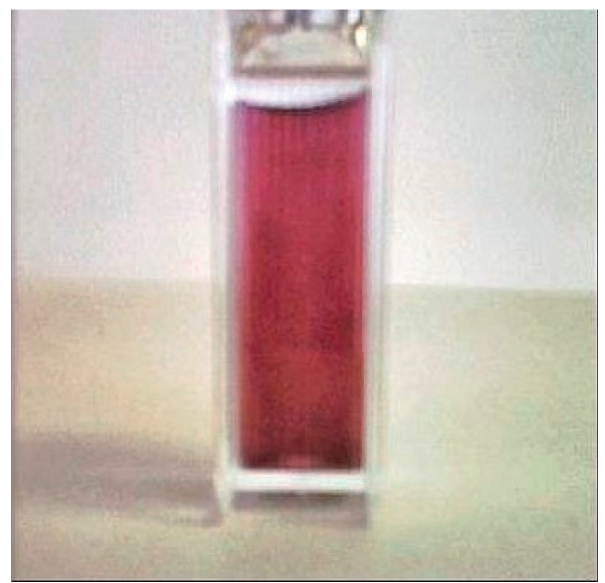

(b)

Figure 1: Positive colour change results for aqueous and methanolic extract reaction with $1 \mathrm{mM} \mathrm{AgNO}_{3}$ solution: (a) $\mathrm{AgNO}_{3}$ solution before mixing with the extract; (b) after mixing the $\mathrm{AgNO}_{3}$ solution with the extract, yellowish-brown colour appeared, and the colour changed to brown after $3 \mathrm{~h}$.

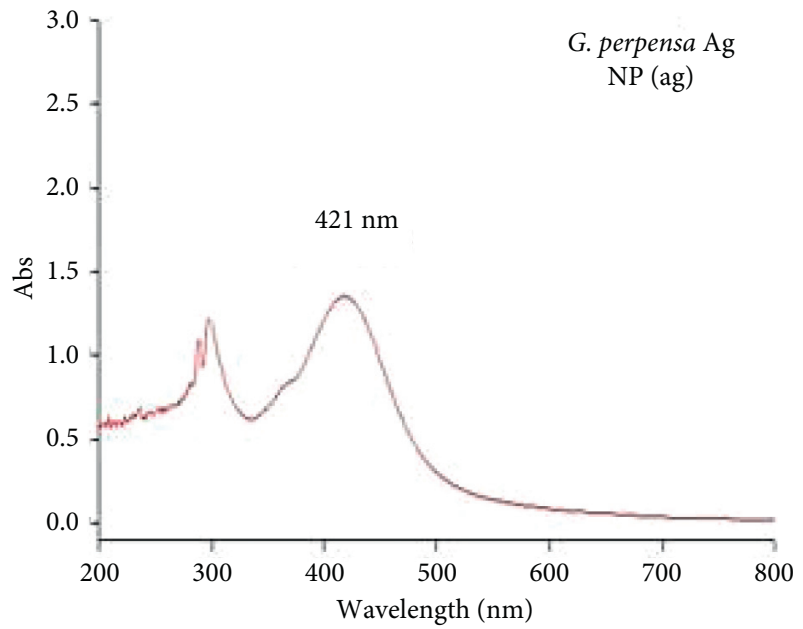

(a)

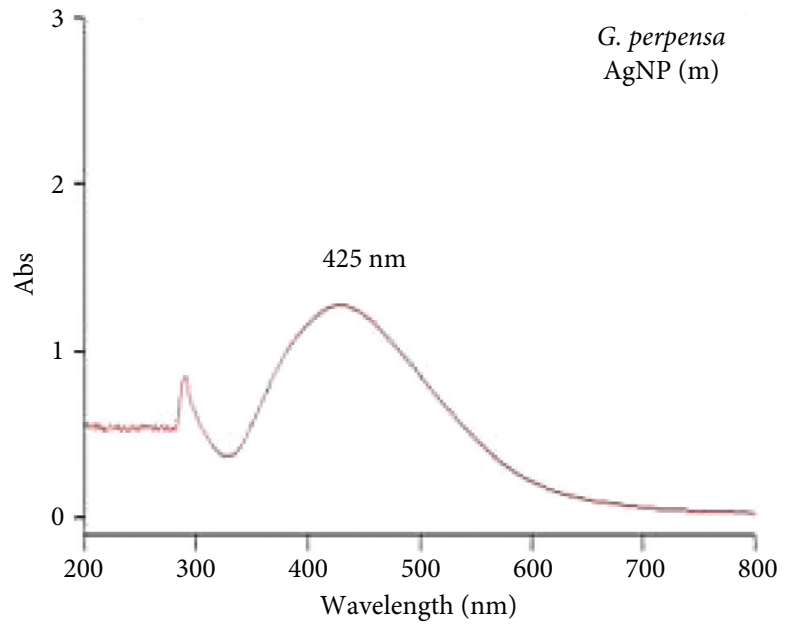

(b)

Figure 2: UV-Vis spectra of (a) aqueous and (b) methanolic G. perpensa-mediated AgNPs.

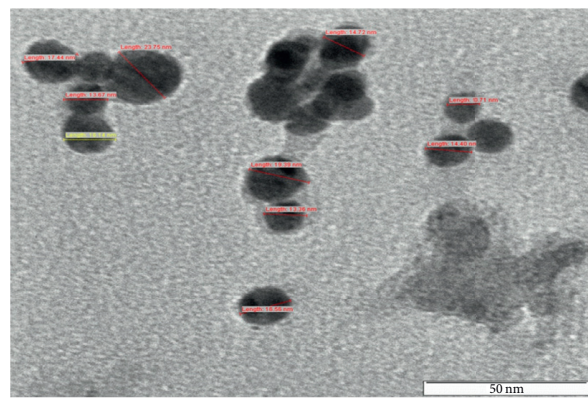

(a)

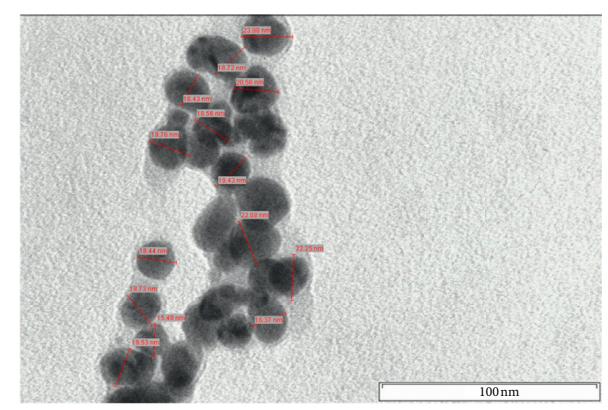

(b)

Figure 3: TEM micrographs of (a) aqueous and (b) methanolic G. perpensa-mediated AgNPs. 


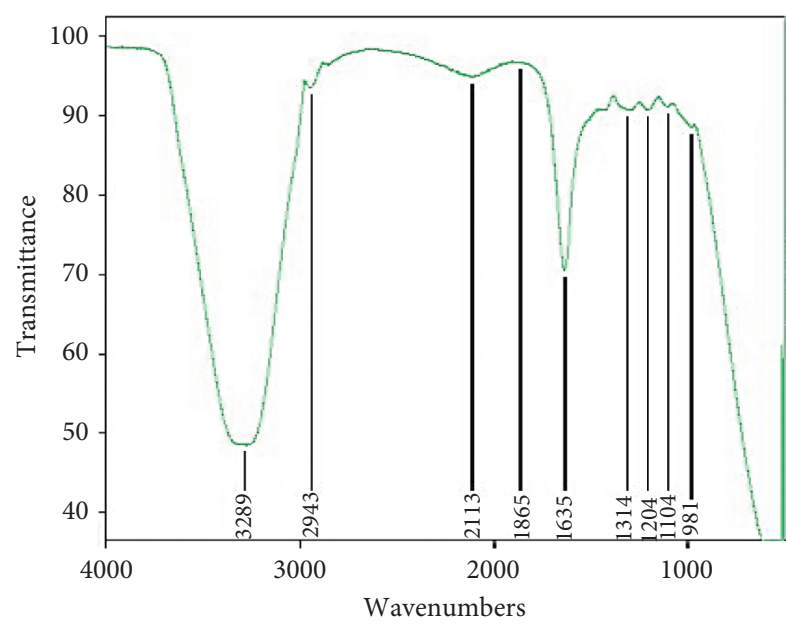

(a)

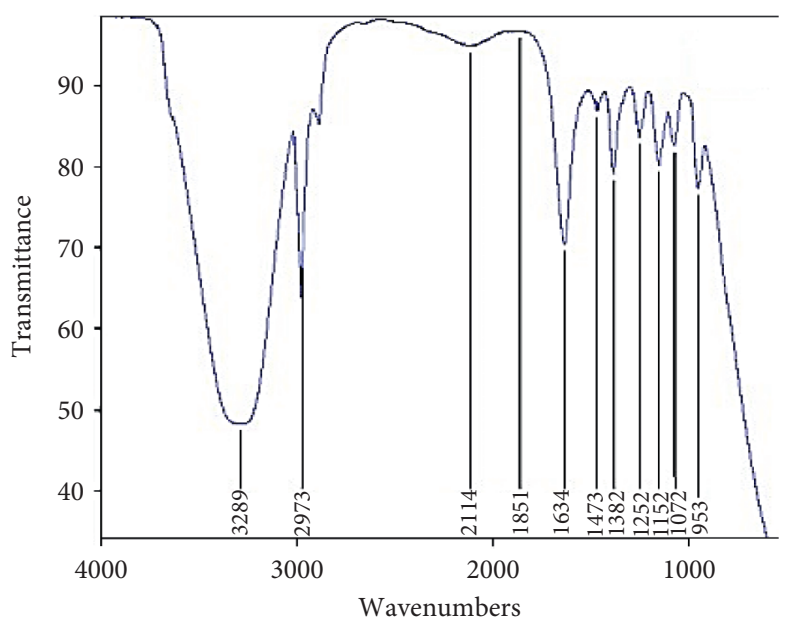

(b)

FIgURE 4: FTIR spectra of (a) aqueous and (b) methanolic G. perpensa-mediated AgNPs.

TABle 1: Antibacterial activity of AgNPs from the aqueous and methanolic leaf extracts of G. perpensa.

\begin{tabular}{|c|c|c|c|c|}
\hline \multirow{3}{*}{ Bacteria } & \multicolumn{4}{|c|}{ Zone of inhibition (mm) } \\
\hline & \multicolumn{2}{|c|}{ G. perpensa AgNPs } & \multicolumn{2}{|c|}{ Controls } \\
\hline & Aqueous $(30 \mu \mathrm{g} / \mathrm{ml})$ & Methanolic $(30 \mu \mathrm{g} / \mathrm{ml})$ & DMSO & $\mathrm{AgNO}_{3}(30 \mu \mathrm{g} / \mathrm{ml})$ \\
\hline (1) E. coli B3578 & $8.7 \pm 0.3$ & $8.5 \pm 0.5$ & 0 & $6.7 \pm 0.0$ \\
\hline (2) E. coli U10948 & $8.0 \pm 0.5$ & $8.7 \pm 0.6$ & 0 & $6.5 \pm 0.5$ \\
\hline (3) E. coli $\mathrm{P} 4055$ & $8.3 \pm 0.6$ & $9.0 \pm 0.5$ & 0 & $6.0 \pm 0.0$ \\
\hline (4) S. aureus S6158 & $7.8 \pm 0.3$ & $7.3 \pm 0.3$ & 0 & $7.5 \pm 0.0$ \\
\hline (5) S. aureus P4215 & $8.8 \pm 0.3$ & $8.5 \pm 0.5$ & 0 & $6.7 \pm 0.3$ \\
\hline (6) S. aureus S5878 & $7.0 \pm 0.9$ & $7.5 \pm 0.5$ & 0 & $6.3 \pm 0.3$ \\
\hline
\end{tabular}

However, because chemical agents used when preparing these NPs affect their biocompatibility and pose environmental problems, biosynthesized AgNPs have been the subject of research recently.

The antibacterial activity of the AgNPs synthesized by $G$. perpensa plant extracts was investigated against Gramnegative and Gram-positive bacteria using the disc diffusion method. In this experiment, DMSO was used as a negative control and also proved to be a safe solvent, which offered no interference with the results obtained in the assay. The diameter of inhibition zones ( $\mathrm{mm}$ ) around each well with AgNP solution is presented in Table 1. MIC was recorded as the lowest concentration at which no visible growth of the tested bacteria was observed (Table 2).

Synthesized AgNPs overall exhibited good antimicrobial activity against both Gram-positive and Gram-negative studied bacteria, with varying degrees, as suggested by the produced zone of inhibition (Table 1). Slightly larger zones of inhibition were observed with the Gram-negative bacteria compared with the Gram-positive bacteria after treatment with both the G. perpensa extract-mediated AgNP preparations. The highest activity was seen against Gram-negative E. coli $\mathrm{P} 4055(9.0 \mathrm{~mm})$, and the lowest activity was seen against Gram-positive $S$. aureus S5878 (7.0 mm) after treatment with aqueous preparation of $G$. perpensa extractmediated AgNPs. However, the highest activity was seen against Gram-negative E. coli U10948 $(8.7 \mathrm{~mm})$, and the lowest activity was seen against Gram-positive $S$. aureus S6158 $(7.3 \mathrm{~mm})$ after treatment with the methanolic $G$. perpensa extract-mediated AgNPs (Table 1). These activity variations can be attributed to the different properties that each bacterial strain has which constitute its mechanism of inhibition [27]. Particularly, cell wall composition as Grampositive bacteria are said to possess a cell wall consisting of a thick layer of polysaccharide which is hard to be penetrated by NPs, while the opposite is true with Gram-negative bacteria [25]. These findings correspond with previous reports by Sánchez-López et al. [28], which showed the selectivity of AgNPs against both the Gram-positive and Gram-negative species of bacteria.

Notably, both G. perpensa extract-mediated AgNP preparations showed significantly $(p<0.05)$ higher antimicrobial activity ranging from 7.0 to $9.0 \mathrm{~mm}$ against tested bacteria, compared with the positive control $\mathrm{AgNO}_{3}$ (6.0-6.7 $\mathrm{mm}$ range). These findings were expected since it has been shown that biosynthesized AgNPs possess an enhanced antimicrobial activity said to be due to the combined use of silver and the plant extract, as silver reduced in nanoform increases its surface area, thus making it more reactive, and the plant extract enhances the therapeutic efficacy of AgNPs due to its good antibacterial efficacy [29]. 
TABLE 2: Minimum inhibitory concentration of AgNPs synthesized from aqueous and methanolic leaf extracts of $A$. dubius and $G$. perpensa.

\begin{tabular}{lccc}
\hline Bacteria & \multicolumn{2}{c}{ MIC $(\mu \mathrm{g} / \mathrm{ml})$} \\
& & $\begin{array}{c}\text { Pqueous } \\
\text { AgNPs }\end{array}$ & Methanolic AgNPs \\
(1) E. coli B3578 & A. dubius & 6.3 & 6.3 \\
(2) E. coli & A. perpensa & 6.3 & 6.3 \\
U10948 & G. perpensa & 6.3 & 6.3 \\
(3) E. coli P4055 & A. dubius & 12.5 & 6.3 \\
(4) S. aureus & G. perpensa & 3.2 & 12.5 \\
S6158 & G. dubius & 12.5 & 6.3 \\
(5) S. aureus & A. dubius & 12.5 & 12.5 \\
P4215 & G. perpensa & 6.3 & 6.3 \\
(6) S. aureus & A. dubius & 12.5 & 12.5 \\
S5878 & G. perpensa & 3.2 & 6.3 \\
\hline
\end{tabular}

Moreover, both aqueous and methanolic preparations of G. perpensa-mediated AgNPs generally exhibited lower MIC values across all tested bacteria ranging from 3.2 to $12.5 \mu \mathrm{g} /$ $\mathrm{ml}$ as shown in Table 2. A lower MIC value exhibited by the AgNPs against bacteria is said to be of great significance in the health care delivery system, as this could provide the patient with a smaller dosage requirement, thus limiting or even preventing harmful side effects [30]. Overall, these findings revealed that good antibacterial activity was achieved at lower doses with both preparations of the $G$. perpensa-mediated AgNPs against all tested bacterial strains, suggesting that G. perpensa-mediated AgNPs were good antimicrobial agents.

\section{Conclusion}

Silver nanoparticles were successfully synthesized using the plant extract of G. perpensa. These NPs were very stable, and all showed efficient antibacterial activity against a range of tested Gram-positive and Gram-negative bacteria at low doses, thus proving to be good antimicrobial agents.

\section{Data Availability}

The SEM and TEM images, the UV-Vis and FTIR spectra, and the biological data used to support the findings of this study are available from the corresponding author upon request.

\section{Conflicts of Interest}

The authors declare that there are no conflicts of interest regarding the publication of this paper.

\section{Acknowledgments}

The National Research Foundation of South Africa and the Durban University of Technology are acknowledged for financial and infrastructural support.

\section{References}

[1] I. Khan, K. Saeed, and I. Khan, "Nanoparticles: properties, applications and toxicities," Arabian Journal of Chemistry, vol. 12, no. 7, pp. 908-931, 2019.

[2] S. Lee and B.-H. Jun, "Silver nanoparticles: synthesis and application for nanomedicine," International Journal of Molecular Sciences, vol. 20, no. 4, p. 865, 2019.

[3] A.-C. Burduşel, O. Gherasim, A. M. Grumezescu, L. Mogoantă, A. Ficai, and E. Andronescu, "Biomedical applications of silver nanoparticles: an up-to-date overview," Nanomaterials, vol. 8, no. 9, p. 681, 2018.

[4] P. Patel, P. Agarwal, S. Kanawaria, S. Kachhwaha, and S. L. Kothari, "Plant-based synthesis of silver nanoparticles and their characterization," in Nanotechnology and Plant Science, pp. 271-288, Springer, Berlin, Germany, 2015.

[5] M. Ovais, A. Khalil, M. Ayaz, I. Ahmad, S. Nethi, and S. Mukherjee, "Biosynthesis of metal nanoparticles via microbial enzymes: a mechanistic approach," International Journal of Molecular Sciences, vol. 19, no. 12, p. 4100, 2018.

[6] H. A. Salam, P. Rajiv, M. Kamaraj, P. Jagadeeswaran, S. Gunalan, and R. Sivaraj, "Plants: green route for nanoparticle synthesis," International Research Journal of Biological Sciences, vol. 1, pp. 85-90, 2012.

[7] D. Mubarakali, N. Thajuddin, K. Jeganathan, and M. Gunasekaran, "Plant extract mediated synthesis of silver and gold nanoparticles and its antibacterial activity against clinically isolated pathogens," Colloids and Surfaces B: Biointerfaces, vol. 85, no. 2, pp. 360-365, 2011.

[8] D. S. Sheny, J. Mathew, and D. Philip, "Phytosynthesis of Au, $\mathrm{Ag}$ and $\mathrm{Au}-\mathrm{Ag}$ bimetallic nanoparticles using aqueous extract and dried leaf of Anacardium occidentale," Spectrochimica Acta Part A: Molecular and Biomolecular Spectroscopy, vol. 79, no. 1, pp. 254-262, 2011.

[9] R. Shanmugam and L. V. Bharath, "Mechanism of plant-mediated synthesis of silver nanoparticles-a review on biomolecules involved, characterization and antibacterial activity," Chemico-Biological Interactions, vol. 273, pp. 219-227, 2017.

[10] E. Burlacu, C. Tanase, N.-A. Coman, and L. Berta, "A review of bark-extract-mediated green synthesis of metallic nanoparticles and their applications," Molecules, vol. 24, no. 23, p. 4354, 2019.

[11] B. Bergman, C. Johansson, and E. Soderback, "The NostocGunnera symbiosis," New Phytologist, vol. 122, no. 3, pp. 379-400, 1992.

[12] M. A. Ngwenya, A. Koopman, and R. Williams, Zulu Botanical Knowledge: An Introduction, National Botanical Institute, Durban, South Africa, 2003.

[13] E. J. Mendes, "Haloragaceae," in Flora Zambesiaca, vol. 4, Managing Committee, London, UK, 1978.

[14] A. Hutchings, A. H. Scott, G. Lewis, and A. Cunningham, Zulu Medicinal Plants: An Inventory, University of Natal Press, Pietermaritzburg, South Africa, 1996.

[15] M. Nkomo, B. N. Nkeh-Chungag, L. Kambizi, E. J. Ndebia, and J. E. Iputo, "Antinociceptive and anti-inflammatory properties of Gunnera perpensa (Gunneraceae)," African Journal of Pharmacy and Pharmacology, vol. 4, pp. 263-269, 2010.

[16] B. E. Van Wyk and N. Gericke, People's Plants. A Guide to Useful Plants of Southern Africa, Briza Publications, Pretoria, South Africa, 2000.

[17] M. F. Doyle and R. Scogin, "A comparative phytochemical profile of the Gunneraceae," New Zealand Journal of Botany, vol. 26, no. 4, pp. 493-496, 1988. 
[18] S. E. Drewes, F. Khan, S. F. Van Vuuren, and A. M. Viljoen, "Simple 1,4-benzoquinones with antibacterial activity from stems and leaves of Gunnera perpensa," Phytochemistry, vol. 66, no. 15, pp. 1812-1816, 2005.

[19] S. P. Dubey, M. Lahtinen, and M. Sillanpää, "Green synthesis and characterizations of silver and gold nanoparticles using leaf extract of Rosa rugosa," Colloids and Surfaces A: Physicochemical and Engineering Aspects, vol. 364, no. 1-3, pp. 34-41, 2010.

[20] L. G. Matasyoh, J. C. Matasyoh, F. N. Wachira, M. G. Kinyua, A. W. T. Muigai, and T. K. Mukiama, "Chemical composition and antimicrobial activity of the essential oil of Ocimum gratissimum L. growing in eastern Kenya," African Journal of Biotechnology, vol. 6, no. 6, 2007.

[21] J. Eloff, "A sensitive and quick microplate method to determine the minimal inhibitory concentration of plant extracts for bacteria," Planta Medica, vol. 64, no. 8, pp. 711-713, 1998.

[22] S. Jain and M. S. Mehata, "Medicinal plant leaf extract and pure flavonoid mediated green synthesis of silver nanoparticles and their enhanced antibacterial property," Scientific Reports, vol. 7, no. 1, pp. 158-167, 2017.

[23] P. Uznanski, J. Zakrzewska, F. Favier, S. Kazmierski, and E. Bryszewska, "Synthesis and characterization of silver nanoparticles from (bis)alkylamine silver carboxylate precursors," Journal of Nanoparticle Research, vol. 19, no. 3, p. $121,2017$.

[24] R. A. Hamouda, M. H. Hussein, R. A. Abo-elmagd, and S. S. Bazawir, "Synthesis and biological characterization of silver nanoparticles derived from the cyanobacterium Oscillatoria limnetica," Nature: Scientific Reports, vol. 9, no. 1, p. 13071, 2019.

[25] Y. N. Slavin, J. Asnis, U. O. Häfeli, and H. Bach, "Metal nanoparticles: understanding the mechanisms behind antibacterial activity," Journal of Nanobiotechnology, vol. 15, no. 1, p. $65,2017$.

[26] C. H. Ramamurthy, M. Padma, I. D. Mariya samadanam et al., "The extra cellular synthesis of gold and silver nanoparticles and their free radical scavenging and antibacterial properties," Colloids and Surfaces B: Biointerfaces, vol. 102, pp. 808-815, 2013.

[27] L. Wang, C. Hu, and L. Shao, "The antimicrobial activity of nanoparticles: present situation and prospects for the future," International Journal of Nanomedicine, vol. 12, pp. 1227-1249, 2017.

[28] E. Sánchez-López, D. Gomes, G. Esteruelas et al., "Metalbased nanoparticles as antimicrobial agents: an overview," Nanomaterials, vol. 10, no. 2, p. 292, 2020.

[29] Y. Qing, L. Cheng, R. Li et al., "Potential antibacterial mechanism of silver nanoparticles and the optimization of orthopedic implants by advanced modification technologies," International Journal of Nanomedicine, vol. 13, pp. 3311-3327, 2018.

[30] C. Dipankar and S. Murugan, "The green synthesis, characterization and evaluation of the biological activities of silver nanoparticles synthesized from Iresine herbstii leaf aqueous extracts," Colloids and Surfaces B: Biointerfaces, vol. 98, pp. 112-119, 2012. 